\title{
Cocoon orientation in the nests of red mason bees (Osmia bicornis) is affected by cocoon size and available space
}

\author{
Hajnalka Szentgyörgyi, Michał Woyciechowski
}

\author{
Institute of Environmental Sciences, Jagiellonian University, Gronostajowa 7, 30-387 Kraków, Poland
}

Received 16 January 2012 - Revised 13 October 2012 - Accepted 9 November 2012

\begin{abstract}
Proper orientation of cocoons in linearly structured nests can be crucial for the survival of hatching bees. Nevertheless, misoriented cocoons appear in nature in notable proportions. A detailed analysis of sex, space available for cocoon spinning, cocoon size, and nest diameter in the red mason bee (Osmia bicornis) showed that smaller males are more prone to misorientation than larger females. Generally, smaller individuals of both sexes are more often misoriented because smaller larvae disregard the direction of the entrance during cocoon construction. Moreover, cocoons in stems of smaller diameter are less often misoriented than bees in wider nests. Our results suggest that cocoon size and available space are the most important traits affecting cocoon orientation.
\end{abstract}

Osmia bicornis / nest construction / cocoon orientation / cocoon size

\section{INTRODUCTION}

Cocoon orientation and the process of emergence in linear wasp and bee nests have raised interest for decades. There are thorough and detailed reviews concerning the nesting biology of these insects (Krombein 1967; Vicens et al. 1993). Most linear nests share a number of common features: (1) cylindrical cells follow each other lengthwise and are separated by partitions built by the female, (2) a partition is always smooth and concave on the posterior wall of the cell, while rough and convex on the anterior, (3) cells in most cases contain only one egg with provision, and (4) the sequence of sexes in the nest is stable and characteristic for the species, usually with females located deeper in the nest, while males closer to the entrance (Krombein 1967). Although such serial nest

Corresponding author: H. Szentgyörgyi,

hajnalka.szentgyorgyi@uj.edu.pl

Manuscript editor: Peter Rosenkranz structure is common, emergence can pose difficulties for the offspring. Cooper in 1957 (after Johnson 1980) noticed that the wasp Euodynerus $f$. foraminatus (de Saussure) selects nesting sites with borings snugly adjusted to their bodies. In consequence, orientation of larvae in the direction of the entrance of the nest is required or otherwise a misoriented individual will kill its siblings located deeper in the nest while trying to chew its way out of the nest. On the other hand, Krombein (1967) found that if a pupa or prepupa dies before emergence, the sibling located deeper in the nest must chew through an extra partition wall which may not always be physically possible for hatching bees, and can lead to their death. In other words, a dead or misoriented individual may be the cause of death for siblings located deeper in the stem and could therefore reduce the mother's fitness. Nonetheless, Osmia lignaria propinqua Cresson produce a notable number (approximately $23 \%$, mainly males) of misoriented cocoons in natural conditions 
(Torchio 1980). Interestingly, only a small fraction of these misoriented cocoons fails to emerge, namely the large-bodied females which are unable to turn around in their cells and in effect die in the nest, whereas males and smaller females successfully leave their nests.

Few studies have attempted to find the stimuli that determine correct orientation in nests. Some possible stimuli include gravity for species with vertical nests, provision placement in the cell, or the shape and texture of the partition walls between cells (for review see: Torchio 1980). In vertical nests, gravity is clearly the main stimulus for correct orientation. Torchio (1980) found that in laboratory condition, not a single cocoon was misoriented in vertical nests with entrance facing upwards. In horizontal nests, gravity cannot act as a stimulus; therefore, Torchio (1980) suggested that differences in the angulations of the partition walls can help the larvae to construct properly oriented cocoon.

We attempted to characterize the physical traits affecting cocoon orientation in the megachilid bee Osmia bicornis, which is a typical mass-provisioning, univoltine bee that constructs linear, serial nests (Michener 2000) with homomorphic cell structure (Vicens et al. 1993) and a significant portion of misoriented cocoons under natural conditions (personal observation). We based our study on the results of Torchio (1980) who already showed how small nest diameter and nest position (vertical vs. horizontal) affect cocoon orientation, and described the process of cocoon spinning in the closely related $O$. lignaria propinqua. He suggested that cocoon orientation in horizontal nests is affected by available space for cocoon spinning, based on differences found between nests with two different diameters: 6 and $7 \mathrm{~mm}$. In his study, cocoons of $O$. lignaria propinqua were more often misoriented in nests with a 7-mm diameter (23\% misoriented) than in thinner, 6$\mathrm{mm}$ nests (only $0.7 \%$ misoriented). However, nest diameter does not necessarily mean less space for each cocoon. In O. bicornis, males are significantly smaller than females, therefore females are more tightly packed and have less available space than males in the same nest. Small females of most wasp species were also shown to provision their offspring less effectively than large ones and produce smaller progeny, while in bees no such clear relationship is visible (for review see: Bosch and Vicens 2006). In O. bicornis this pattern is less pronounced, since small females have larger progeny than themselves, while large females smaller (Seidelmann et al. 2010). Nevertheless, Seidelmann et al. (2010) found that cocoon mass of offspring did correlate to female body size. Therefore, offspring of smaller or worse provisioning females in tight nests (smaller diameter) can have more space (due to their smaller size) than better provisioned offspring of a large or better provisioning female in a similar sized nest

Herein, we have extended previous analyses (Torchio 1980) by measuring not only nest diameter but also space available in the nest (based on differences between nest diameter and cocoon width) and cocoon size (calculated from cocoon length and width). Additionally, we tested if nest building females adjust the size of provision and sex ratio of their offspring to nest diameter to ensure efficient emergence. We were interested in finding the trait that most consistently determines or affects cocoon orientation, bearing in mind that some of these traits are either correlated or can limit one another.

\section{MATERIAL AND METHODS}

Red mason bees are solitary, univoltine bees common throughout Europe. In Poland, the first individuals appear in March/April and fly until June. Males emerge approximately 2 weeks before females and die soon after copulation. Females can live up to 5 to 6 weeks, constructing and provisioning their nests. Red mason bee females under natural conditions look for narrow borings, holes, or stems for nest construction. The female first collects a pollen and nectar provision, then lays one egg on the provision, and finally seals the brood cell by building a mud wall. Depending on the length of the nesting cavity, a female can construct up to 20 cells in one nest. Provisioning of a single egg lasts approximately 
a day depending on the weather (personal observation). Eggs hatch within 1-2 weeks after laying and develop through five instars; next, the larva spins a thick cocoon and develops into an adult bee at the beginning of summer. Adult bees then overwinter in their cocoons and emerge in the next spring.

Bees used in this study originated from a breeding colony at the Institute of Environmental Sciences, Jagiellonian University, Kraków, Poland (19 $54^{\prime} 0.52^{\prime \prime}$ E, $\left.50^{\circ} 1^{\prime} 32.55^{\prime \prime} \mathrm{N}\right)$. The colony was established in 2004 using cocoons purchased from BioDar Ecological Bee Breeding Company (2004), Poland. The present study started in 2008 and lasted until 2010. Bees were given standardized, natural nesting material in the form of reed stems (Wilkaniec and Giejdasz 2003). Reed was collected from nearby locations (lakes and other water bodies) and cut into ca. $15 \mathrm{~cm}$ long pieces, so that one end was naturally closed by a node in the reed stem, while the other end was left open (cut before the next stem node). The stems used in this study had a mean inner diameter between 6.2 and $9.3 \mathrm{~mm}$ in 2008/2009 and 5.7$10.4 \mathrm{~mm}$ in $2009 / 2010$. All reeds were placed horizontally. Stems with developing bees were left in the colony from March until February the next year. Then, at the beginning of February, stems were moved to a climatic chamber with a stable temperature of $5{ }^{\circ} \mathrm{C}$. Bees-while still being in their nestswere then taken from the chamber to the laboratory $\left(20^{\circ} \mathrm{C}\right)$ in mid-April in 2009 and at the beginning of May in 2010 for measurements. We analysed 24 reeds containing 181 cocoons in 2009 and 95 reeds containing 662 cocoons in 2010. Each removed cocoon was measured (length and width using a digital calliper up to $0.02-\mathrm{mm}$ accuracy), and the orientation of the cocoon inside the cell was classified as "correct"- towards the entrance, or "misoriented"towards the blind end of the nest (Figure 1).

Instead of using raw values of cocoon length and width-which is limited by reed diameter but can be compensated by building somewhat longer cocoons (Torchio 1980) - we have calculated cocoon size as $C_{(\text {size })}=\sqrt{\text { length } \times \text { width. }}$. This value showed a highly significant correlation to body mass at the time of removal $\left(n=280, R^{2}=0.8163, P<0.0001\right)$. We have also correlated cocoon size calculated as cocoon length $\times$ width, as in Bosch and Vicens (2002); however, this correlation was somewhat weaker
$\left(R^{2}=0.7738, P<0.0001\right)$ for our population. To assess available space in the nest, the difference between reed diameter and cocoon width was calculated.

To assess potential differences between years due to varying weather and nesting conditions, the ratio of live adults, ratio of sexes, and ratio of misoriented cocoons were compared between years and separately for sexes using G-test ( $\alpha$ after Bonferroni's correction $=0.0166$ ). Reed diameter and cocoon size (regardless of cocoon orientation) were compared using one-way ANOVA (STATISTICA 9 2008), in case of cocoon size-separately for sexes.

The probability of misorientation of cocoons was modelled at the individual level with a generalized linear mixed model (GLIMMIX macro in SAS 9.1 (2009)) with a logit link function, binomial error variance, and degrees of freedom approximated by the Satterthwaite method (Krackow and Tkadlec 2001). Nest identity was included in all analyses as random factor to account for relatedness between offspring, while sex and year were introduced as fixed effects. Cocoon size and available space were the covariates and were analysed separately due to lack of independence between them.

For testing possible adjustments made by the nest building female to nest diameter, the following parameters were analysed in relation to reed diameter: (1) cocoon size and (2) sex ratio. Additionally, relationship between the ratio of misoriented cocoons and nest diameter was analysed. For all correlations, Spearman's rank correlation was applied.

\section{RESULTS}

During the two examined seasons, 119 reed stems were opened and 970 cells were checked for cocoons. Basic parameters of stems and bees were similar in both years: mean stem diameter, mean number of cells per nest, proportion of fully developed cocoons in the nest, cocoon size, and sex ratio of imagos (Table I). Cocoon orientation was more often correct in both years (Table I) reaching 90 and $97 \%$ for females, while 71 and $81 \%$ for males in 2009 and in 2010 , respectively. The ratio of correctly oriented females was significantly larger than that of 
Figure 1. Schematic structure of a red mason bee nest built in a standard horizontal reed stem, showing the orientation of cocoons and details of nest structure.

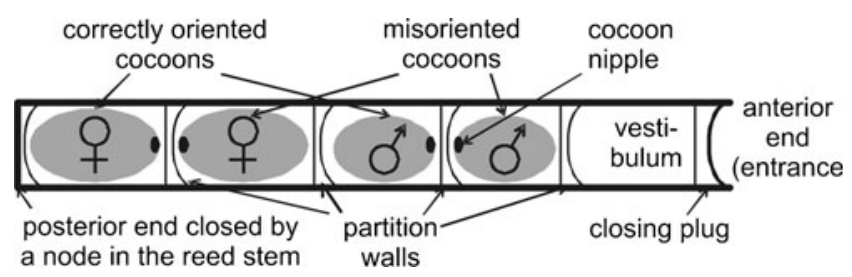

males in both years $(2009, G=10.4, P=0.001$; 2010, $G=22.5, P<0.00001)$.

Misoriented individuals showed significant differences in cocoon size and available space compared to correctly oriented individuals (Table II). Comparing cocoon size showed that large cocoons were more often correctly oriented than smaller ones; however, in this case, years differed significantly, but not sexes (Table II, Figure 2). Cocoons with more available space were also generally more often misoriented than cocoons tightly fitting to their nest. Additionally, sexes differed in their response (Table II, Figure 3). Nest as a random factor both in the case of cocoon size and available space showed significant differences (Table II).

Cocoon size was only correlated to reed diameter for female progeny $(\rho=0.25, P<$ 0.0001 , but not for male ( $\rho=0.02$, NS; Figure 4$)$.
Nest building females did not adjust the sex ratio of their progeny to nest size $(\rho=0.17, \mathrm{NS})$. Reed diameter and the ratio of misoriented cocoons per nest showed a clear positive correlation $(\rho=0.30, P<0.05$; Figure 5).

\section{DISCUSSION}

Red mason bees analysed in the present study showed similar cocoon size and nest structure (number of cells/nest) in both years. Most of the bees in our study were correctly oriented. Nevertheless, the proportion of misoriented individuals was not negligible, reaching 29 and $10 \%$ for males and females, respectively. Overrepresentation of the smaller sex (males) in both years, together with the generally smaller cocoon size of misoriented individuals, confirms the earlier findings of Torchio (1980), suggesting that misorientation depends on

Table I. Number and diameter (mean \pm SE) of reeds, number of cells examined, number of red mason bee cocoons, cocoon size of females and males (mean \pm SE), and their orientation in the reed nest in 2009 and 2010.

\begin{tabular}{|c|c|c|c|}
\hline Parameter & 2009 & 2010 & $P$ \\
\hline No. of examined reeds & 24 & 95 & \\
\hline $\begin{array}{l}\text { Mean diameter of reed } \\
\text { stems }(\mathrm{mm})\end{array}$ & $7.3 \pm 0.27$ & $7.5 \pm 0.1$ & $F(1,80)=0.24 P=0.63, \mathrm{NS}$ \\
\hline $\begin{array}{l}\text { No. of cells with fully } \\
\text { developed cocoons/cells }\end{array}$ & $\begin{array}{r}181 / 194 \\
(93 \%)\end{array}$ & $\begin{array}{r}662 / 776 \\
(85 \%)\end{array}$ & $G=0.59 P=0.44, \mathrm{NS}$ \\
\hline 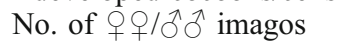 & $86 / 95$ & $286 / 376$ & $G=1.07 P=0.30, \mathrm{NS}$ \\
\hline $\begin{array}{l}\text { Misoriented/correctly } \\
\text { oriented } q 9 \text { cocoons }\end{array}$ & $\begin{array}{l}9 / 77 \\
\quad(10 \%)\end{array}$ & $\begin{array}{r}10 / 276 \\
(3 \%)\end{array}$ & $G=5.65 P=0.02, \mathrm{NS}$ \\
\hline $\begin{array}{l}\text { Misoriented/correctly } \\
\text { oriented } \hat{\partial} \partial^{\lambda} \text { cocoons }\end{array}$ & $\begin{array}{l}28 / 67 \\
(29 \%)\end{array}$ & $\begin{array}{l}73 / 303 \\
(19 \%)\end{array}$ & $G=4.27 P=0.04, \mathrm{NS}$ \\
\hline Cocoon size of $q$ 우 $(\mathrm{mm})$ & $9.03 \pm 0.05$ & $8.97 \pm 0.03$ & $F(1,368)=0.98 \quad P=0.32, \mathrm{NS}$ \\
\hline Cocoon size of $\widehat{\partial} \widehat{\partial}(\mathrm{mm})$ & $7.67 \pm 0.06$ & $7.61 \pm 0.03$ & $F(1,467)=1.02 \quad P=0.31, \mathrm{NS}$ \\
\hline
\end{tabular}

Last column shows the results of statistical comparisons (G-test with Bonferroni's correction for comparing number of cells, adults and misoriented/oriented cocoons between years, while one-way ANOVAs to compare cocoon size and body mass of sexes between years) for the tested parameters 
Table II. Results of generalized linear mixed model analysis with a logit link function and binomial error variance for the effects of cocoon size and available space on cocoon orientation of red mason bees.

\begin{tabular}{lccc}
\hline Source of variation & $d f$ & $F$ & $P$ \\
\hline Cocoon size & 829 & 0.46 & 0.5 \\
Sex & 96.4 & 8.30 & $\underline{0.005}$ \\
Year & 808 & 32.85 & $\leq \underline{0.0001}$ \\
Cocoon size & & \\
Nest ID estimate $\pm \mathrm{SE}=0.62 \pm 0.21 ; Z=3.01 ; P=\underline{0.001}$ & & $\leq \underline{0.0001}$ \\
Available space & 585 & 20.32 & 0.09 \\
Sex & 67.5 & 13.04 & $\leq \underline{0.001}$ \\
Year & 183 & 13.82 & \\
Available space & & \\
Nest ID estimate $\pm \mathrm{SE}=0.79 \pm 0.28 ; Z=2.78 ; P=\underline{0.0027}$ & & \\
\hline
\end{tabular}

In all analyses, nest was introduced as a random factor, while sex and year as fixed effects

The underlined $P$ values are statistically significant

available space in the nest. Analyses of available space and cocoon size showed that as expected, cocoon size together with available space were the traits that affected most dramatically cocoon orientation. Nest identity explained some of the observed differences, but this is no surprise since nest identity determined nest width and the maximum space an individual can use. Additionally, nest building females in the present study clearly adjusted provision size of female progeny to nest diameter, but on the contrary provisioning male offspring equally. Contrary to the earlier findings of Tepedino and Torchio (1989), females in our study did not adjust their progeny's sex ratio to nest diameter, but used all available sizes regardless of their progeny's sex. However, Tepedino and Torchio (1989) used a different species than the one examined here, namely the North American O. lignaria propinqua. Both species share similar nesting biology, but differences in their behaviour or decision making cannot be excluded. Discrepancies in provisioning rate or shifts in sex ratio due to nestbuilding female's body size in various bee and wasp species were shown already by Bosch and Vicens (2006).

The correlation between nest diameter and the ratio of misoriented cocoons per nest also confirms the findings of Torchio (1980). Unlike in our study, Torchio used only two different nests (with diameters of 6 and $7 \mathrm{~mm}$ ) to

Figure 2. Cocoon size ( $\sqrt{\text { length } \times \text { width }})$ of misoriented and correctly oriented red mason bee cocoons.

Crosses indicate mean values, rectangular shapes indicate $\mathrm{SE}$, straight lines, SD. For detailed statistics, see the text and Table II.

FEMALE

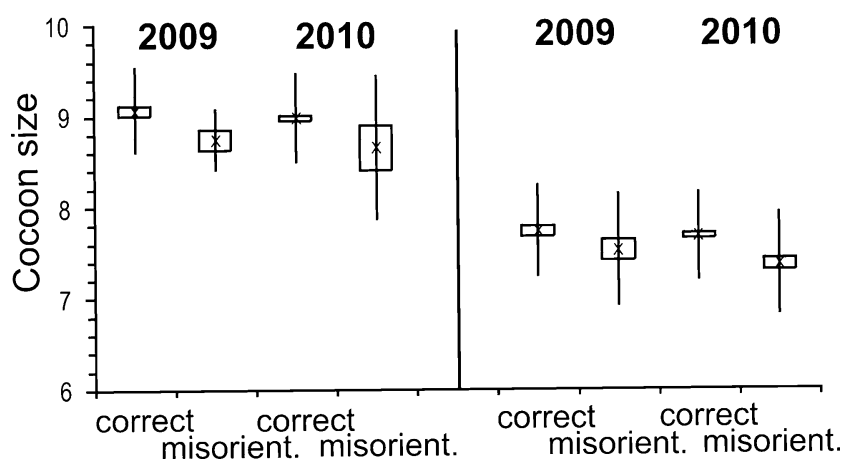


Figure 3. Available space (difference of nest diameter and cocoon width) for misoriented and correctly oriented red mason bee cocoons. Crosses indicate mean values, rectangular shapes indicate $\mathrm{SE}$, straight lines, SD. For detailed statistics, see the text and Table II.

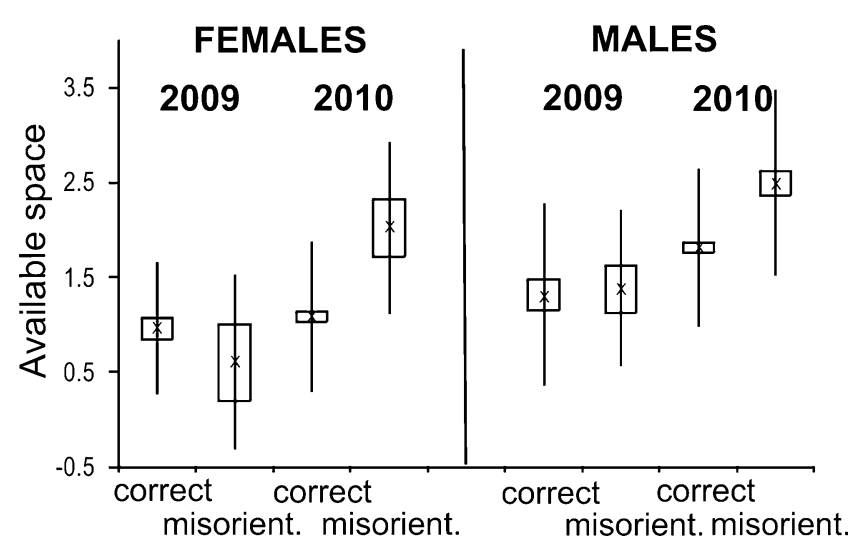

compare the effect of nest size, while we have examined a whole spectrum of sufficient nest sizes. Both Torchio's and our results show that the ratio of misoriented cocoons is lower in thinner nests.

Space-dependent cocoon orientation may be explained by cocoon construction. Already Torchio (1980) had observed that relatively small larvae compared to their cell size (thus with more available space) spin cocoons in a different way than larger larvae, more snugly adjusted (having less space) to their cells. Small larvae attach individual strands to all or almost all wall surfaces forming a cushion made of strands before spinning the first layer of the cocoon. Larger individuals or those that better

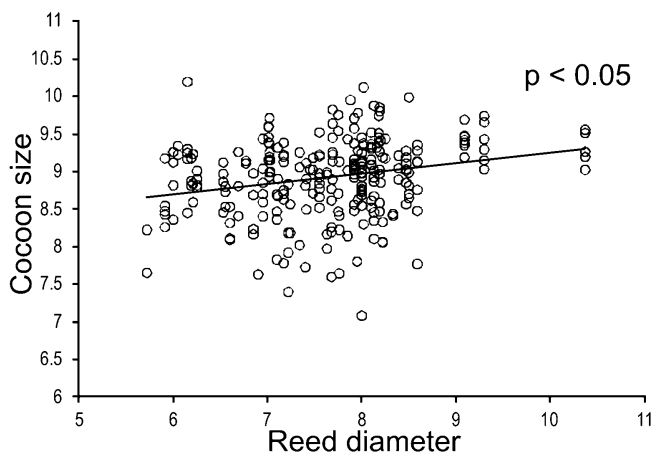

Figure 4. Correlation between cocoon size ( $\sqrt{\text { length } \times \text { width }})$ of female and male red mason bees and reed stem diameter (millimeters) used for nesting. The solid line represents the relationship between nest diameter and female cocoon size. For detailed statistics, see the text. fit their cell size use only a few strands and do not form a cushion to support the larvae, but attach the outer layer of the cocoon directly to the ventral and basal surface of the cell. This observation suggests that perception of restricted space in the cell activates different mechanisms/ procedures of cocoon spinning (Torchio 1980).

Other studies suggest possible environmental cues determining the orientation of the larvae inside the cell. Matthew and Kislow in 1973 using reversely placed provision masses concluded that $O$. lignaria cocoons determine their orientation based on the placement of provision within the cell. However, few years later, Johnson (1980) conducting a similar, though not identical experiment found that $O$. lignaria

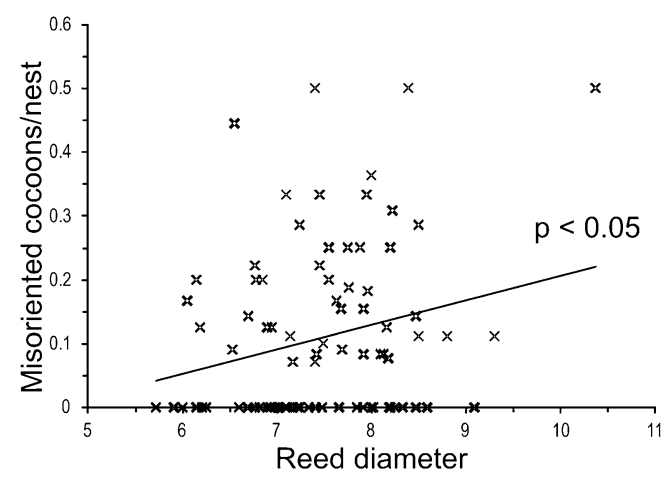

Figure 5. Correlation between reed stem diameter used for nesting by red mason bees and the ratio of misoriented cocoons found in these nests regardless of their sex. For detailed statistics, see the text. 
did not rely on provision placement. Similarly, the same year, Torchio (1980) using O. lingnaria propinqua as a model concluded that in horizontal linear nests (in which the effect of gravity on cocoon orientation can be excluded), differences in the structure of the partition walls serve most probably as a clue for proper cocoon orientation. In most species, including the red mason bee, the posterior wall is usually smooth and concave, while the anterior is rough and convex (Krombein 1967). This difference in wall structure is caused by the wall building process itself. The egg-laying female brings mud particles in its mandibles to the nest, gluing them first to the cell's cylindrical inner surface. After creating an initial mud-ring, she narrows the ring by adding new layers of mud until the cell is closed (personal observation), and also pushes and smoothens the anterior surface using the front of her head (Krombein 1967). The larvae can probably recognize both the structural difference of walls and the space available in the cell. According to these factors, larvae either adjust their orientation towards the entrance during spinning the first (outer layer) of their cocoons, or if sufficient space is available, simply disregard their orientation inside the cell. In the second case, they construct the above-mentioned cushion supporting the larvae and in consequence orient the spinning of the cocoon more randomly.

Construction of the cocoon either according to or disregarding the direction of the nest entrance suggests possible selection on proper cocoon orientation since bees usually orient their cocoons properly even when enough space is available. Unfortunately, no detailed data are available showing the effect of misorientation on the success of emergence from such cocoons. The only documented effect was given by Torchio (1980) who noted that large, misoriented females failed to emerge; however, this effect was not observed in smaller females. We observed that small males can turn around and in some cases even push their way through other small siblings and emerge successfully; however, this behaviour was not noted in the case of large individuals (personal observation).
In summary, misorientation of cocoons in linear bee nests is clearly dependent on individual cocoon size and available space in the cell. Additionally, due to significant sex-related size differences and possible adjustments made by the nest building female, it can be more pronounced in the smaller sex, i.e. in males, but less in larger, better adjusted to nest size sex, i.e. females. The significantly higher ratio of correctly oriented cocoons indicates that selection on proper orientation during spinning may be relevant, and further studies are required in this direction.

\section{ACKNOWLEDGMENTS}

We wish to thank Dr. Joanna Rutkowska for constructive comments on statistical analyses and the anonymous reviewers for their valuable comments and suggestions on our manuscript. This study was supported by the 7th EU Framework Programme STEP (Status and Trends of European Pollinators) 244090 and DS/WBINOZ/INOS/761/2006-2009.

L'orientation du cocon dans les nids de l'abeille maçonne (Osmia bicornis) est influencée par la taille du cocon et l'espace disponible.

Abeille maçonne / construction du nid / orientation du cocon / taille du cocon / Megachilidae

Die Ausrichtung des Kokons im Nest der Roten Mauerbiene (Osmia bicornis) wird durch die Größe des Kokons und den verfügbaren Raum beeinflusst.

Osmia bicornis / Nestkonstruktion / Kokonausrichtung / Kokongröße / Megachilidae

Open Access This article is distributed under the terms of the Creative Commons Attribution License which permits any use, distribution, and reproduction in any medium, provided the original author(s) and the source are credited.

\section{REFERENCES}

BioDar Ecological Bee Breeding Company (2004) www. biodar.com.pl 
Bosch, J., Vicens, N. (2002) Body size as an estimator of production cost in a solitary bee. Ecol. Entomol. 27, 129-137

Bosch, J., Vicens, N. (2006) Relationship between body size, provisioning rate, longevity and reproductive success in females of the solitary bee Osmia cornuta. Behav. Ecol. Sociobiol. 60, 26-33

GLIMMIX macro SAS 9.1 (2009) SAS Institute Inc.: http://www.sas.com

Johnson, M.D. (1980) Observation on cocoon orientation in Osmia (Osmia) lignaria lignaria Say (Hymenoptera: Megachilidae). J. Kansas. Entomol. Soc. 53, 581-586

Krackow, S., Tkadlec, E. (2001) Analysis of brood sex ratios: implications of offspring clustering. Behav. Ecol. Sociobiol. 50, 293-301

Krombein, K.V. (1967) Trap-Nesting Wasps and Bees: Life Histories, Nests, and Associates. Smithsonian Press, Washington DC

Matthews, R.W., Kislow, C.J. (1973) Cocoon orientation in a megachilid bee: larval response to pollen placement. Environ. Entomol. 3, 157-158
Michener, C.D. (2000) The bees of the world. John Hopkins University Press, Baltimore

Seidelmann, K., Ulbrich, K., Mielenz, N. (2010) Conditional sex allocation in the red mason bee, Osmia rufa. Behav. Ecol. Sociobiol. 64, 337-347

STATISTICA 9 (2008) Statsoft Inc. www.statsoft.com

Tepedino, V.J., Torchio, P.F. (1989) The influence of nest-hole selection on sex ratio and progeny size in Osmia lignaria propinqua (Hymenoptera: Megachilidae). Ann. Entomol. Soc. Am. 82, 355-360

Torchio, P.F. (1980) Factors affecting cocoon orientation in Osmia lignaria propinqua Cresson (Hymenoptera: Megachilidae). J. Kansas. Entomol. Soc. 53(2), 386-400

Vicens, N., Bosch, J., Blas, M. (1993) Análisis de los nodis de algunas Osmia (Hymenoptera, Megachilidae) nidificantes en cavidades preestablecidas. Orsis 8, 41-52

Wilkaniec, Z., Giejdasz, K. (2003) Suitability of nesting substrates for the cavity-nesting bee Osmia rufa. J. Apic. Res. 42(3), 29-31 